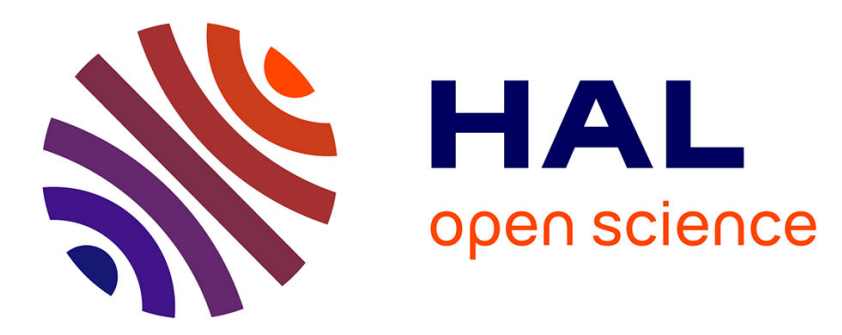

\title{
Small angle neutron scattering experiments in smectic A and smectic B phases of diluted liquid crystal copolysiloxanes
}

\author{
S. Lecommandoux, Laurence Noirez, Monique Mauzac, F. Hardouin
}

\section{To cite this version:}

S. Lecommandoux, Laurence Noirez, Monique Mauzac, F. Hardouin. Small angle neutron scattering experiments in smectic A and smectic B phases of diluted liquid crystal copolysiloxanes. Journal de Physique II, 1994, 4 (12), pp.2249-2255. 10.1051/jp2:1994259 . jpa-00248129

HAL Id: jpa-00248129

https://hal.science/jpa-00248129

Submitted on 1 Jan 1994

HAL is a multi-disciplinary open access archive for the deposit and dissemination of scientific research documents, whether they are published or not. The documents may come from teaching and research institutions in France or abroad, or from public or private research centers.
L'archive ouverte pluridisciplinaire HAL, est destinée au dépôt et à la diffusion de documents scientifiques de niveau recherche, publiés ou non, émanant des établissements d'enseignement et de recherche français ou étrangers, des laboratoires publics ou privés. 


\title{
Small angle neutron scattering experiments in smectic $A$ and smectic B phases of diluted liquid crystal copolysiloxanes
}

\author{
S. Lecommandoux $\left({ }^{1}\right)$, L. Noirez $\left({ }^{2}\right)$, M. Mauzac $\left({ }^{1}\right)$ and F. Hardouin $\left({ }^{1}\right)$ \\ (') Centre de Recherche Paul Pascal, Université Bordeaux I, Av. A. Schweitzer, 33600 Pessac, \\ France \\ (2) Laboratoire Léon Brillouin, CEA-CNRS/CE Saclay, 91191 Gif-sur-Yvette, France
}

(Received 8 June 1994, received in final form 11 July 1994, accepted 20 July 1994)

\begin{abstract}
Résumé. - Par diffusion des neutrons aux petits angles, nous observons que la chaîne de polysiloxanes « en peigne» conserve une conformation de type oblate en phase smectique A lorsqu'on diminue le nombre de mésogènes par unité répétée. Ce comportement est différent de celui des polymères «en haltère » puisqu'à taux de mésogènes équivalent, ces derniers perdent toute anisotropie. Enfin, nous montrons pour la première fois l'existence d'une anisotropie de type oblate en phase smectique $B$.
\end{abstract}

\begin{abstract}
Small Angle Neutron Scattering experiments were carried out on liquid crystal « sideend fixed " polysiloxanes : we observe that the polymer backbone keeps an oblate shape in the smectic A phase when the proportion of mesogens is reduced. This behavior is different from «side-on fixed » polymers since their anisotropic conformation vanishes at low mesogenic rate. Finally, we show for the first time an oblate anisotropic conformation in the smectic $B$ phase.
\end{abstract}

\section{Introduction.}

Side-chain thermotropic liquid crystal polymers have drawn much interest in the past few years. In particular, the influence in the bulk of nematic or smectic A mesogenic order on the backbone conformation of the polymer has been extensively studied through small angle neutron scattering experiments (SANS) [1-13].

Two qualitatively different situations have shown a strong anisotropy of the backbone conformation induced by macroscopic orientation of the lateral mesogenic groups. The first situation deals with «side-on fixed» homopolymers. In this case, a strong nematic « jacketed » structure is observed. Such a structure can give an outstretched shape of the main chain with some " prolate » backbone anisotropy (ratio of radii of gyration $R_{\|} / R_{\perp} \cong 4$ to 6 , referring to the direction of the mesogenic orientation) at low temperatures $[8,9,12]$. The second situation concerns the «side-end fixed » homopolymers for which the backbone exhibits an « oblate » shape in smectic A phases, connected with a confinement of the main chain in a quasi two-dimensional way between two layers of mesogens [2, 7]. In such a case, at low temperatures, the values of « oblate » anisotropic ratio $\left(R_{\|} / R_{\perp}\right)$ are found to be between 2 and 4. 
Therefore, this work aims at answering an important question : is there any significant anisotropy of the main-chain of a « side-end fixed » polymer when the proportion of mesogens is strongly reduced? In addition, our purpose is to compare the results with those obtained with " diluted side-on fixed » polymers [13]. In all cases, the best way to see the « dilution » effect is to study by SANS a copolymer containing only a small proportion of mesogenic units.

\section{Materials.}

The investigated polymers have the following formula :

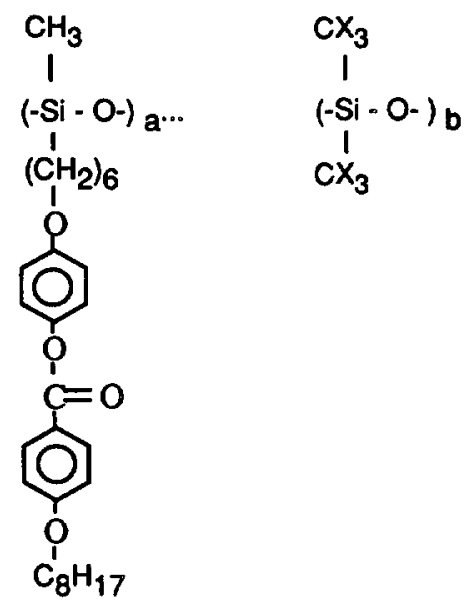

with $\mathrm{X}=\mathrm{H}$ for the non-labelled and $\mathrm{X}=\mathrm{D}$ for the partially labelled polymers.

The initial backbone is a statistical poly(hydrogenomethylsiloxane-co-dimethylsiloxane) of well-defined composition and molecular weight. It is synthesized by acid catalysis equilibration of cyclic octamethyltetrasiloxane (hydrogenated and perdeuterated) and of linear hydrogenomethylsiloxane prepolymer [13]. The mesogenic groups, previously synthesized, are linked to the silane bond by a standard hydrosilylation reaction.

These polymers are noted P6,8(x) where $x$ is the proportion of mesogenic units as defined :

$$
x=a /(a+b) \text { in percent } .
$$

In this study, the value of $x$ is on average $30 \%$.

The number average molecular weights were determined from the number average molecular weight of the initial backbone measured by tonometry $\left(\bar{M}_{\mathrm{n}}\right)$, assuming complete hydrosylilation. The polydispersity index $(I)$ is determined by gel permeation chromatography versus polysiloxane standards. These results are summarized in table I.

Table I. - Average molecular weights $\bar{M}_{\mathrm{n}}$, polydispersity index I and degree of polymerization $\left(\overline{\mathrm{DP}}_{\mathrm{n}}\right)$ for the hydrogenated $(\mathrm{H})$ and deuterated $(\mathrm{D})$ copolysiloxanes.

\begin{tabular}{|c|c|c|c|}
\hline Polymer & $\bar{M}_{\mathrm{n}}$ & $I$ & $\overline{\mathrm{DP}}_{\mathrm{n}}$ \\
\hline I P6,8(30\%)-H & $13800 \pm 3000$ & 1.4 & $80 \pm 5$ \\
\hline II P6,8(30\%)-D & $14100 \pm 3000$ & 1.4 & $70 \pm 5$ \\
\hline
\end{tabular}


For each polymer, the transition temperatures are determined by DSC and by optical measurements. We observed that the transition temperatures of the hydrogenated and the partially deuterated polymers are practically the same. We can claim that the degree of polymerization has reached the plateau corresponding to the polymer regime for which the transition temperatures are independent of the molecular weight. The results are listed in table II.

Table II. - Phase transition temperatures for $\mathrm{P} 6,8(30 \%)$. $\mathrm{g}$ : glassy state, $\mathrm{S}_{\mathrm{B}}$. smectic $\mathrm{B}$ phase, $\mathrm{S}_{\mathrm{A}}$. smectic A phase, $\mathrm{I}$ : isotropic liquid phase. * from DSC (Perkin Elmer DSC7). heating rate of $10^{\circ} \mathrm{C} / \mathrm{mn}$.

\begin{tabular}{|c|c|}
\hline Polymer & Transition Temperatures $\left({ }^{\circ} \mathrm{C}\right)$ \\
\hline I P6,8(30\%)-H & $\mathrm{g} \bullet-2^{*} \bullet \mathrm{S}_{\mathrm{B}} \bullet 41 \bullet \mathrm{S}_{\mathrm{A}} \bullet 104 \bullet \mathrm{I}$ \\
\hline II P6,8(30\%)-D & $\mathrm{g} \bullet-6^{*} \bullet \mathrm{S}_{\mathrm{B}} \bullet 37 \bullet \mathrm{S}_{\mathrm{A}} \bullet 100 \bullet \mathrm{I}$ \\
\hline blend $50 \% \mathbf{I} / 50 \%$ II & $\mathrm{g} \bullet-3^{*} \bullet \mathrm{S}_{\mathrm{B}} \bullet 40 \bullet \mathrm{S}_{\mathrm{A}} \bullet 108 \bullet \mathrm{I}$ \\
\hline
\end{tabular}

\section{Experimental determination of global conformation of the polymers $\mathbf{P 6 , 8}$.}

The small angle neutron scattering (SANS) experiments have been performed by following a procedure described elsewhere [3-7, 14].

A mixture containing an equal amount of hydrogenated polymer $\mathrm{P} 6,8(30 \%)-\mathrm{H}$ and its counterpart $\mathrm{P} 6,8(30 \%)-\mathrm{D}$ deuterated on the backbone was obtained by precipitation in methanol of a solution of these polymers in tetrahydrofuran. As usual, a mixture of 50/50 weight ratio is selected for maximum scattered coherent intensity [7].

Aligned samples could be obtained by cooling them slowly through the isotropic-smectic A phase transition under an external magnetic field $(1.4 \mathrm{~T}$ and oriented perpendiculary to the incident neutron beam). The neutrons scattered by the sample are collected on the SANS- $X Y$ position multidetector " $\mathrm{PAXY}$ » of the Laboratoire Léon Brillouin (CEA/CNRS, CEN Saclay, Orphée reactor).

The quality of the orientation is controlled in situ through the mosaicity of the 001 smectic reflection measured at large angles by neutron diffraction.

At low $q$ values, the incident wavelength was $\lambda=14 \AA$ and the distance between the detector and the sample was $4 \mathrm{~m}$. Consequently the range of the scattering vector $q:$

$$
q=4 \pi \theta / \lambda(2 \theta \text { is the scattering angle ) }
$$

extends between $7 \times 10^{-3} \AA^{-1} \leqslant q \leqslant 0.04 \AA^{-1}$.

The apparent quadratic size $R_{\|}$and $R_{\perp}$ (parallel and perpendicular to the magnetic field) of our polymer are deduced from measurements of the scattering intensity $I(q)$.

We stress that the distribution of the small-angle scattering intensity corresponds only to the conformation of the main-chain alone since the deuteration has been made only on the methyl groups of the polysiloxane chain [7]. 

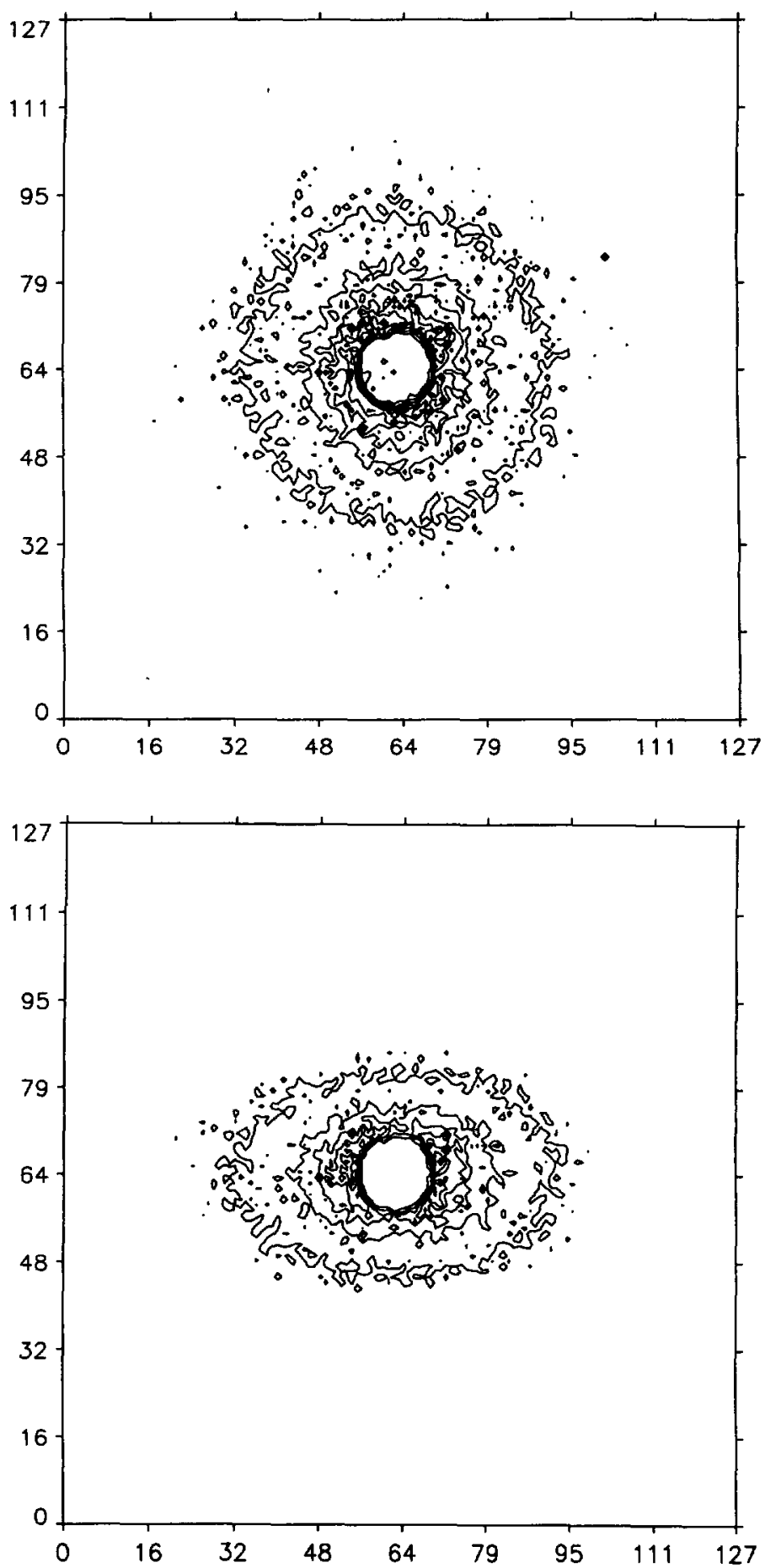

b)

Fig. 1. - Transverse section of intensity scattered by the main-chain of a $\mathrm{P} 6,8(30 \%)$. The white disk in the centre is due to the beam trap. The magnetic field is horizontal. (a) Isotropic liquid $\left(T=115^{\circ} \mathrm{C}\right)$. The backbone conformation is isotropic. (b) Smectic A phase $\left(T=66^{\circ} \mathrm{C}\right)$. The scattering in reciprocal space presents a prolate shape which means that the backbone adopts an oblate conformation in direct space. 
Referring to the Zimm plot representation, we then have in the enlarged Guinier domain $(q R \leqslant 2)$

$$
\begin{aligned}
& I^{-1}\left(q_{\|}\right)=I^{-1}(0)\left(1+q^{2} R_{\|}^{2}\right) \\
& I^{-1}\left(q_{\perp}\right)=I^{-1}(0)\left(1+q_{\perp}^{2} R_{\perp}^{2}\right) .
\end{aligned}
$$

Beside, since in the isotropic phase $R_{\uparrow}^{2}=R_{\perp}^{2}$ the relation $R_{\|}^{2}+2 R_{\perp}^{2}=R_{\mathrm{g}}^{2}$, where $R_{\mathrm{g}}$ is the apparent radius of gyration of the main-chain averaged over all directions [7], is satisfied in the isotropic phase as well as in a uniaxial medium $\left(S_{A}\right.$ and $S_{B}$ phases), we get :

$$
I^{-1}(q)=I^{-1}(0)\left(1+q^{2} R_{\mathrm{g}}^{2} / 3\right) .
$$

\section{Results and discussion.}

Figure 1 displays the scattered iso-intensity distribution for $\mathrm{P} 6,8(30 \%)$ in the $X Y$ plane of the spectrometer: figure la corresponds to the isotropic phase at $115^{\circ} \mathrm{C}$. As expected, no anisotropy can be detected in the intensity distribution. Figure $1 \mathrm{~b}$ corresponds to the smectic $\mathrm{A}$ phase at $66{ }^{\circ} \mathrm{C}$ and the shape of the scattering is clearly anisotropic. Qualitatively speaking, the scattering in the reciprocal space is essentially distributed in the direction parallel to the magnetic field : this immediately indicates that, in direct space, the backbone adopts an oblate shape conformation.

The experimental values of $I^{-1}\left(q_{1}\right)$ versus $q_{1}^{2}$ were determined from the anisotropic distribution of the scattered intensity at different temperatures.

For instance, figure 2 corresponds to the experimental values for P6,8(30\%) in the smectic

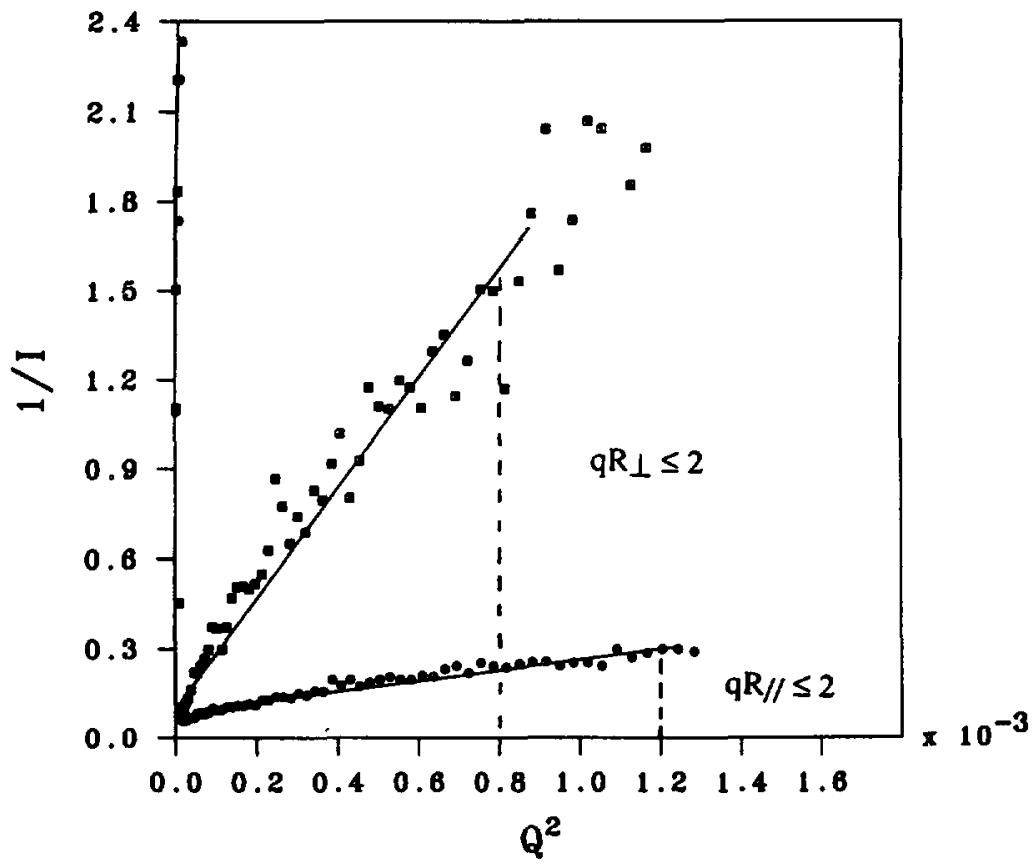

Fig. 2. - Inverse of the SANS intensity $I$ plotted in arbitrary units as a function of $q^{2}$ in the smectic A phase $\left(T=66^{\circ} \mathrm{C}\right)$. For both directions $\|$ and $\perp$, the straight lines are obtained from a least square method in the enlarged Guinier domain $(q R \leqslant 2)$. 


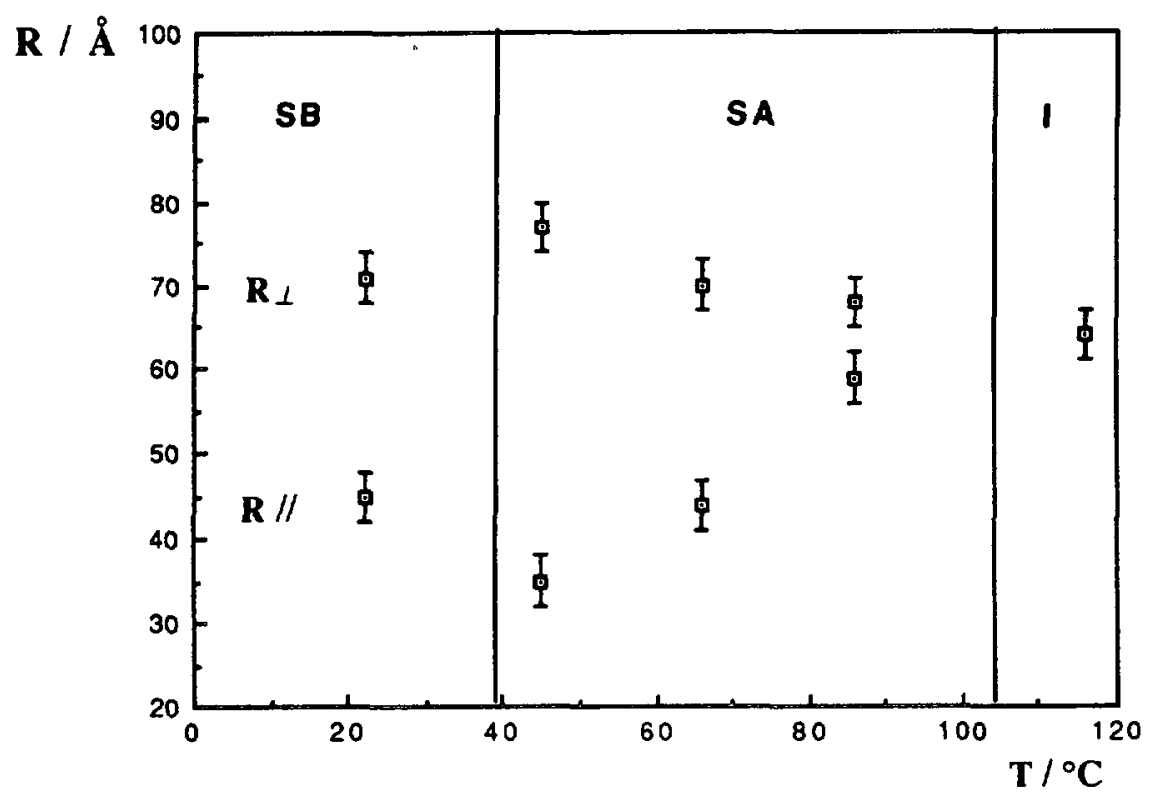

Fig. 3. - Values of the components of the radii of gyration $R_{\|}$and $R_{\perp}$ of the polymer main-chain as function of temperature. As soon as the $S_{A}-I$ transition, the main-chain anisotropy becomes oblate.

A phase at $T=66^{\circ} \mathrm{C}$. At very low $q$ values a micro-segregation effect could explain the enhancement of the scattered intensities $\left(q \leqslant 10^{-2} \AA^{-1}\right)$.

The general features of the temperature dependence of the polymer dimensions $\left(R_{\|}\right.$and $R_{\perp}$ ) are reported in figure 3. In the isotropic phase, $R_{\|}$and $R_{\perp}$ are both equal to about $64 \pm 3 \AA$. On decreasing the temperature, we see in the smectic $\mathrm{A}$ phase an extension of the dimension perpendicular to the magnetic field whereas $R_{\|}$decreases (Fig. 3). Far enough from the I-S $\mathrm{S}_{\mathrm{A}}$ transition, the values of $R_{\|}$and $R_{\perp}$ confirm the chain confinement due to the layers with a rather strong anisotropic oblate shape $\left(R_{\perp} / R_{\|}=2.2\right)$. Moreover, below the $S_{A}-S_{B}$ transition, we show for the first time that a chain anisotropy remains in this $3 D$ ordered smectic phase $\left(S_{B}\right)$ of a « comb-like » polymer. Nevertheless if we compare these values to those obtained at low temperatures in the $S_{A}$ phase, we note a decrease of the oblate anisotropy $\left(R_{\perp} / R_{\|}=1.6\right)$ in the $\mathrm{S}_{\mathrm{B}}$ phase. This result in the $\mathrm{S}_{\mathrm{B}}$ phase corresponds respectively to a small increase of $R_{\|}$together with a small decrease of $R_{\perp}$. This reduced anisotropy could be a consequence of the existence of some intercorrelations between layers due to the $3 \mathrm{D}$ structure.

To conclude, we first bear in mind the effect of decreasing the proportion of mesogenic groups in "side-on fixed » polymer from a homopolymer to copolymer [13] : we observed a considerable reduction of the chain extension and a diminution of the « jacketed » structure in the nematic phase till negligible anisotropy for « $30 \%$ » diluted system.

In contrast with «side-on fixed " polymers, we show that « side-end fixed" polymers preserve an oblate anisotropy even for « $30 \%$ diluted system in $S_{A}$ and $S_{B}$ phases.

These SANS experiments clearly demonstrate two kinds of interactions of the polymer backbone with the mesomorphic order in LC side chain polymers.

The first one, for « side-on fixed " polymer essentially, is an orientational coupling « chaindirector » between the main-chain and the mesogenic parts, the magnitude of which is due mainly to the chemical structure (spacer length, dilution.. ) $[8,9,12]$. Locally, the « side-on » fixation imposes on the polymer backbone to take up an arrangement that preserves the orientation of the bulky mesogenic groups. In the former case the backbone locally follows the 
director and in terms of relaxation process for chain deformation, it is probably necessary to allow distorted nematic. The second one is markedly different, for a large class of " side-end fixed " polymers, there is a translational coupling «chain-layering order » between mainchain and the smectic structure $[2,3,7,10,15-18]$. Due to the «side-end » fixation, the main chain is not compelled to locally align parallel to the mesogenic groups. In any case, at long range the main chain «feels » the smectic structure and is more or less confined between the layers. We suggest that in such a pseudo-2D geometry, the deformation of the chain could be Gaussian without nematic distorsion.

In the latter case, the magnitude of the oblate anisotropy of the chain conformation depends mainly on the strength of the layering order in the $S_{A}$ phase and copolymers including nonmesogenic units leading to a close packing of the mesogens in layers $[19,20]$. Finally, the onset of a 3D smectic $B$ phase brings a new and complex situation even though the chain confinement appears to be retained.

\section{References}

[1] Kirste R. G. and Ohm H. G., Makromol. Chem. Rapid Commun. 6 (1985) 179.

[2] Keller P., Carvalho B., Cotton J. P., Lambert M., Moussa F., Pepy G., J. Phys. Lett. France 46 (1985) 1065.

[3] Moussa F., Cotton J. P., Hardouin F., Keller P., Lambert M., Mauzac M., Pépy G., J. Phys. Lett. France 48 (1987) 1079.

[4] Noirez L., Cotton J. P., Hardouin F., Keller P., Moussa F., Pepy G., Strazielle C., Macromolecules 21 (1988) 2891.

[5] Noirez L., Keller P., Davidson P., Hardouin F., Cotton J. P., J. Phys. France 49 (1988) 1993.

[6] Hardouin F., Noirez L., Keller P., Lambert M., Moussa F., Pepy G., Richard H., Mol. Cryst. Liq. Cryst. 55 (1988) 389.

[7] Noirez L., Ph. D Thesis, Orsay, France (1989).

[8] Méry S., Ph. D Thesis, Bordeaux I, France (1990).

[9] Hardouin F., Méry S., Achard M. F., Noirez L., Keller P., J. Phys. II France 1 (1991) 511 et erratum, J. Phys. II France 1 (1991) 871.

[10] Pépy G., Noirez L., Keller P., Lambert M., Moussa F., Cotton J. P., Strazielle C., Hardouin F., Mauzac M., Richard H., Makromol Chem. 191 (1990) 1383.

[11] Mitchell G. R., Coulter M., Davis F. J., Guo W., J. Phys. II France 2 (1992) 1121.

[12] Hardouin F., Leroux N., Méry S., Noirez L., J. Phys. II France 2 (1992) 271.

[13] Leroux N., Mauzac M., Noirez L., Hardouin F., Liq. Cryst. 16 (1994) 421-428.

[14] a) Cotton J. P., Decker D., Benoît H., Farnoux B., Higgins J., Jannik G., des Cloizeaux J., Picot C., Macromolecules 7 (1974) 863 ;

b) Cotton J. P., Neutron, X-ray and light scattering, P. Linder, Th. Zemb Eds. (Elsevier, 1991).

[15] Davidson P., Noirez L., Cotton J. P.. Keller P., Liq. Cryst. 10 (1991) 111.

[16] Casquilho J. P., Volino F., Mol. Cryst. Liq Cryst. 180B (1990) 357.

[17] Davidson P., Levelut A. M., Liq. Cryst. 11 (1992) 469 ;

Noirez L., Davidson P., Schwarz W., Pépy G., to be published in Liq. Cryst.

[18] Ohm H. G., Kirste R. G., Oberstür R. C., Makromol. Chem. 116 (1988) 1387.

[19] Diele S., Oelsner S., Kuschel F., Higsen B., Ringsdorf H., Makromol. Chem. 188 (1987) 1993.

[20] Diele S., Oelsner S., Kuschel F., Higsen B., Ringsdorf H., Mol. Cryst. Liq. Cryst. 155 (1988) 399. 